\title{
Frequency of orthostatic hypotension in a community based cohort of patients with Parkinson's disease
}

\author{
L M Allcock, K Ullyart, R A Kenny, D J Burn
}

J Neurol Neurosurg Psychiatry 2004;75:1470-1471. doi: 10.1136/jnnp.2003.029413

The frequency of orthostatic hypotension $(\mathrm{OH})$ in cohorts of patients recruited through hospital Parkinson's disease (PD) clinics ranges from $16 \%$ to $58 \%$. However, hospital based cohorts may be subject to ascertainment bias. The aim of this study was to determine the frequency of $\mathrm{OH}$ in a community based population of PD patients and to determine the demographic features of patients with and without $\mathrm{OH}$.

Forty two $(47 \%)$ of patients met the criteria for $\mathrm{OH}$. Subjects with $\mathrm{OH}$ were older than those without $\mathrm{OH}$, but there was no difference in PD disease duration or severity, MMSE or depression rating between the groups.

$\mathrm{T}$ he clinical relevance of orthostatic hypotension $(\mathrm{OH})$ for people with Parkinson's disease (PD) is poorly understood.

Two conflicting studies have included $\mathrm{OH}$ in a risk factor analysis for falls in PD. Wood et al studied 101 patients with $\mathrm{PD}$ and found no difference in the frequency of $\mathrm{OH}$ between fallers and non-fallers. ${ }^{1}$ Gray et al studied 118 patients with $\mathrm{PD}$ and demonstrated a significant difference in fall frequency between those with $\mathrm{OH}$ and those without $\mathrm{OH}^{2}$

$\mathrm{OH}$ may also be a risk factor for cognitive impairment in elderly people. ${ }^{3}{ }^{4}$ The role of $\mathrm{OH}$ as a risk factor for cognitive impairment in PD has not been studied.

Previous studies have suggested that between $43 \%$ and $58 \%$ of patients with $\mathrm{PD}$ have $\mathrm{OH}^{1{ }^{15}}$ Differences in the definition of $\mathrm{OH}$, the methods used to measure postural blood pressure changes and variations in timing of recordings may all have contributed to disparity in prevalence estimates. Studies to date have concentrated on cohorts of patients recruited through hospital PD clinics. This may introduce ascertainment bias and make the findings less relevant to the PD community as a whole.

The aim of this study was to determine the frequency and demographic associations of $\mathrm{OH}$ in a community based population of patients with PD.

\section{METHODS}

General practices (GPs) in the Sunderland area (County Durham, UK) were invited to take part in the study. A nurse specialist screened records for READ coded key diagnostic terms such as "Parkinson's disease" or "parkinsonism", or for medications used to treat PD. Patients with probable primary degenerative parkinsonism were invited through their own GP to attend for assessment. Only those patients meeting the United Kingdom Parkinson's Disease Society (UKPDS) Brain Bank Criteria for PD were recruited.

All subjects were assessed in the morning, in a fasting state, and having not taken any medications since the night before. Assessment included grading of severity of PD with the Hoehn and Yahr scale ${ }^{6}$ and the motor subsection of the Unified Parkinson's Disease Rating Scale (UPDRS), ${ }^{7}$ Mini
Mental State Examination (MMSE), ${ }^{8}$ Geriatric Depression Score (GDS), ${ }^{9}$ and the Montgomery and Åsberg Depression Rating Scale (MADRS). ${ }^{10}$

A list of medications taken by each subject was recorded. Doses of dopamine agonists and controlled release preparations of levodopa were converted to equivalent doses of levodopa (mg) using previously suggested scales, ${ }^{11}{ }^{12}$ allowing direct comparison of dopaminergic medication between groups. $\beta$-Blockers, calcium antagonists, angiotensin converting enzyme inhibitors, angiotensin II receptor antagonists, nitrates, $\alpha$-adrenoceptor blocking agents, and thiazide diuretics were defined as hypotension inducing medications.

Blood pressure was measured using a validated digital blood pressure monitor (A \& D UA-767; PMS (Instruments) Ltd, Berkshire, UK). ${ }^{13}$ We followed the American College of Neurologists guidelines for measuring $\mathrm{OH}$, which require a three minute stand following a 10 minute supine rest period. Readings were taken at one and two minutes as local experience has demonstrated that blood pressure falls after two minutes are unlikely to occur. $\mathrm{OH}$ was defined as a drop in systolic blood pressure after standing greater than or equal to $20 \mathrm{~mm} \mathrm{Hg}$ or to less than $90 \mathrm{~mm} \mathrm{Hg}{ }^{14}$ Postural blood pressure changes were recorded on two separate occassions for each patient.

The study had ethical approval from the Sunderland Local Research Ethics Committee. Population data for each of the screened practices was provided by the Primary Care Trust.

\section{Statistics}

Data are presented as mean and standard deviation, and median values. Non-parametric continuous data were analysed using the Mann-Whitney U test. Ordinal and categorical data, such as the Hoehn and Yahr score and the number of additional medications were compared with the $\chi^{2}$ test.

\section{RESULTS}

Forty one practices took part in the study, covering a population of 237564 . A total of 270 patients were identified by the screening of whom $104(38.5 \%)$ agreed to take part in the study. Out of these 89 patients met the UKPDS Brain Bank Criteria for PD and were recruited.

A comparison of patients who consented to take part and those who withheld consent is given in table l. The subjects recruited were younger and less dependent than their nonconsenting counterparts.

Forty two $(47 \%)$ of patients met the criteria for $\mathrm{OH}$ on at least one occasion.

Patients with $\mathrm{OH}$ were older (mean (SD) age 72.6 (8.1) years) than those without $\mathrm{OH}(68.2$ (9.6) years), $\mathrm{p}=0.02$. Those patients with $\mathrm{OH}$ were taking more hypotension inducing medications in addition to levodopa than those without, but the difference did not reach statistical significance $(\mathrm{p}=0.08)$.

Abbreviations: $\mathrm{OH}$, orthostatic hypotension; PD, Parkinson's disease 
Table 1 Comparison of patients agreeing to take part in the study and those not consenting to further assessment

\begin{tabular}{llll}
\hline & $\begin{array}{l}\text { Participants } \\
(\mathbf{n}=\mathbf{8 9 )}\end{array}$ & $\begin{array}{l}\text { Non-participants } \\
(\mathbf{n}=166)\end{array}$ & $\mathbf{p}$ \\
\hline Age & & & \\
Mean & 70.2 & 77.0 & $<0.001^{*}$ \\
Median & 71.8 & 77.7 & \\
SD & 9.21 & 8.83 & \\
Sex (male:female) & $51: 38$ & $75: 91$ & $0.06 \dagger$ \\
Own home & 88 & 131 & $<0.001 \dagger$ \\
Residential care & 1 & 21 & \\
Nursing home & 0 & 14 & \\
\hline \multicolumn{2}{l}{ *Mann-Whitney U test. } & & \\
t $\chi^{2}$ test. & &
\end{tabular}

Of 60 patients taking only levodopa as antiparkinsonian therapy $33(55 \%)$ had $\mathrm{OH}$. Only seven patients were taking dopamine agonists without levodopa, of whom two (28.5\%) had $\mathrm{OH}$. The dose of levodopa in the levodopa-only treated patients was significantly higher than the levodopa equivalent dose calculated for patients treated with agonists alone (levodopa group $441.3 \mathrm{mg}$ per day $v$ agonist group $251.4 \mathrm{mg}$ per day, $\mathrm{p}=0.007$ ) making it impossible to attribute any difference in proportion with $\mathrm{OH}$ to a class effect of different antiparkinsonian medications.

There was no difference in disease duration or severity between those with $\mathrm{OH}$ and those without. Similarly, cognitive function and rating of depression did not differ between the groups.

\section{DISCUSSION}

Door-to-door surveys are the gold standard for recruitment of community based PD cohorts, but can only cover a small population base. Population screening by review of GP records is an accepted method to cover a wider population base and hence was the method chosen for the present study. ${ }^{15}$

Previous studies of patients with PD recruited from hospital clinics have shown that up to $58 \%$ may have $\mathrm{OH}^{1}{ }^{15}$ We had anticipated that a community based cohort of patients might be older and more frail than those attending hospital clinics, and that the prevalence of $\mathrm{OH}$ might be somewhat higher in this group. The finding of a prevalence figure for $\mathrm{OH}$ similar to those in hospital based studies may in part be a reflection of difficulties with recruitment of older, more frail, patients from the community (see table 1) but may also relate to decreased sensitivity for detection of $\mathrm{OH}$ with intermittent blood pressure recording as compared to continuous beat-to-beat monitoring. ${ }^{16}$

Age was the only factor that was significantly higher in the $\mathrm{OH}$ group than in those without $\mathrm{OH}$. Neurocardiovascular instability is associated with ageing, ${ }^{17}$ and it is possible that the findings demonstrated in our study are a reflection of age related vascular changes occurring independently of PD related pathology.

In contrast with previous reports, ${ }^{518}$ our study did not demonstrate any association with disease severity or duration. Recent studies have, however, documented that $\mathrm{OH}$ can occur even in early $\mathrm{PD}^{19}$ while reduced tracer uptake on cardiac meta-iodobenzylguanidine (MIBG) scanning does not correlate with disease duration, although it is correlated with disease severity. ${ }^{20}$ It may be, therefore, that a subgroup of PD patients may have a more aggressive disease course and that $\mathrm{OH}$ might be a marker for these patients. Prospective longitudinal follow up of our study cohort will establish the rate of progression of motor disability and cognitive decline in patients with and without $\mathrm{OH}$, and may help to address this hypothesis.

\section{Authors' affiliations \\ L M Allcock, K Ullyart, R A Kenny, D J Burn, Department of Neurology, Sunderland Royal Hospital and Institute for Ageing and Health, University of Newcastle, UK \\ LMA has an NHS Research and Development Training Fellowship. \\ $\mathrm{KU}$ is funded by the PPP Foundation. \\ Competing interests: none declared}

Correspondence to: Dr L M Allcock, Parkinson's Disease Research Unit, Department of Neurology, Sunderland Royal Hospital, Sunderland, UK; I.m.allcock@ncl.ac.uk

Received 30 September 2003

In revised form 12 January 2004

Accepted 13 January 2004

\section{REFERENCES}

1 Wood BH, Bilclough JA, Bowron A, et al. Incidence and prediction of falls in Parkinson's disease: a prospective multidisciplinary study. J Neurol Neurosurg Psychiatry 2002;72:721-5

2 Gray P, Hildebrand K. Fall risk factors in Parkinson's disease. J Neurosci Nurs 2000;32:222-8.

3 Stout NR, Galloway S, Ayre G, et al. Cognitive function is impaired in elderly patients with orthostatic hypotension. J Am Geriatr Soc 1999;47:s20.

4 Viramo P, Luukinen $\mathrm{H}$, Koski K, et al. Orthostatic hypotension and cognitive decline in older people. J Am Geriatr Soc 1999;47:600-4.

5 Senard JM, Rai S, Lapeyre-Mestre M, et al. Prevalence of orthostatic hypotension in Parkinson's disease. J Neurol Neurosurg Psychiatry 1997;63:584-9.

6 Hoehn MH, Yahr MD. Parkinsonism. Onset, progression and mortality. Neurology 1967; 17:427-42.

7 Fahn S, Elton RL, members of the UPDRS Development Committee. Unified Parkinson's Disease Rating Scale. In: Fahn S, Calne DB, Lieberman A, eds. Recent developments in Parkinson's disease. Florham Park, NJ: Macmillan Health Care Information, 1987:153-63.

8 Folstein MF, Folstein SE, McHugh PR. "Mini-mental state". A practical method for grading the cognitive state of patients for the clinician. J Psychiatr Res 1975; 12:189-98.

9 Yesavage JA, Brink TL, Rose TL, et al. Development and validation of a geriatric depression screening scale: a preliminary report. J Psychiatr Res 1982; 17:37-49.

10 Montgomery SA, Asberg M. A new depression scale designed to be sensitive to change. Br J Psychiatry 1979;134:382-9.

11 Hobson DE, Pourcher E, Martin WR. Ropinirole and pramipexole, the new agonists. Can J Neurol Sci 1999;26(suppl 2):S27-33.

12 The Deep Brain Stimulation for Parkinson's disease Study Group. Deep brain stimulation of the subthalamic nucleus or the pars interna of the globus pallidus in Parkinson's disease. N Engl J Med 2001;345:956-63.

13 Rogoza AN, Pavlova TS, Sergeeva MV. Validation of A\&D UA-767 device for the self-measurement of blood pressure. Blood Press Monit 2000;5:227-31.

14 Kaufmann H. Consensus statement on the definition of orthostatic hypotension, pure autonomic failure and multiple system atrophy. Clin Auton Res 1996;6:125-6.

15 Schrag A, Ben-Schlomo S, Quinn NP. Cross sectional prevalence survey of idiopathic Parkinson's disease and parkinsonism in London. BMJ 2000;321:21-2.

16 Shaw FE, Wears R, Gammage MD. Is continuous blood pressure measurement necessary for cardiovascular investigation in older patients? Age Ageing 2002;31(suppl 2):21.

17 Masaki KH, Schatz IJ, Burchfiel CM, et al. Orthostatic hypotension predicts mortality in elderly men: the Honolulu Heart Program. Circulation 1998;98:2290-5.

18 Meco G, Pratesi L, Bonifati V. Cardiovascular reflexes and autonomic dysfunction in Parkinson's disease. J Neurol 1991;238:195-9.

19 Bonuccelli U, Lucetti C, Del Dotto P, et al. Orthostatic hypotension in de novo Parkinson disease. Arch Neurol 2003;60:1400-4.

20 Hamada K, Hirayama M, Watanabe H, et al. Onset age and severity of motor impairment are associated with reduction of myocardial 123I-MIBG uptake in Parkinson's disease. J Neurol Neurosurg Psychiatry 2003;74:423-6. 